\title{
Cultural Sustainability and the Negotiation of Public Space - The Case of Indrachowk Square, Kathmandu, Nepal
}

\author{
Bijay Singh $^{1} \&$ Martina Maria Keitsch ${ }^{2}$ \\ ${ }^{1}$ Tribhuvan University Kathmandu, Nepal \\ ${ }^{2}$ Department of Product Design, Norwegian University of Science and Technology, Norway \\ Correspondence: Bijay Singh, Tribhuvan University Kathmandu, Nepal. E-mail: bjlals@hotmail.com
}

Received: March 27, 2014 Accepted: May 19, 2014 Online Published: May 21, 2014

doi:10.5539/jsd.v7n3p129 URL: http://dx.doi.org/10.5539/jsd.v7n3p129

\begin{abstract}
One of the major challenges today is to learn how to share spaces that have been made for all. This is not just relating to the use of old public space, it is also about creating new common space. Apparently, cultural, social and economic activities of certain societal groups influence access to public space, but these activities do not necessarily include all users or contribute to its overall sustainability. The aim of this article is to analyse how stakeholder negotiate and conduct activities, how these form and change, how they permit and confine access to public space for different users, in which ways they allow to negotiate access, and how they relate to sustainability with focus on a case study on local groups that are associated with Indrachowk Square, Kathmandu. Results of this study show that triple-bottom line sustainability is profoundly influenced by cultural activities. Further, there must be access opportunities for the various users of space. Access to space appears as dynamic process closely linked to negotiations about how to use it. In order to get and maintain access, competence development related to knowledge, values, feelings and cultural beliefs connected with the space plays an important role, and achieving this competence can be in turn encouraged by fostering specific cultural and sustainability related activities.
\end{abstract}

Keywords: urban space, stakeholder-driven change, culture, architecture, design

\section{Introduction}

Recently, architecture theorists have started to integrate elements of social theory and philosophy into their methodological frameworks (Casey, 1998; Veseley, 2004) and architectural practice is increasingly connecting planning with socio-cultural concerns as well (Hamdi, 2010; Oppenheimer, Dean, \& Hursley, 2002; Day \& Parnell, 2003). Considering ecological, mental-cultural, socio-political and economic dependencies related to public space, the authors of this article follow the rationale that public space is mentally, socially and materially constructed (Lefebvre, 1991) and that one can perceive it as a network and phenomenon of intertwined beliefs, policies and practices.

A major challenge for any urban society lies in facilitating satisfying relationships between the built environment, ecology and peoples activities. In this context, cultural sustainability is becoming an increasingly important aspect of sustainable development, and could be a powerful driver for development with community-wide social, economic and environmental impacts. Development interventions that are responsive to the cultural context and the particularities of a place and community, and advance a human-centered approach to development are most effective, and likely to yield sustainable, inclusive and equitable outcomes (UNESCO, 2012). Some authors even claim that culture should be considered the fourth pillar of sustainability (Nurse, 2006). Wessels (2006) states that adding culture on its own merits to the ecological, economic and social pillar creates a holistic approach to sustainability. Cultural sustainability looks at ways to improve life-quality and leave a viable inheritance for future generations. This requires the recognition of local cultural values, equal rights and providing support for community-based or participatory approaches. Further, the promotion of cultural diversity and the preservation and conservation of tangible and intangible (local) cultural heritage are considered key aspects for cultural sustainability. In this article an investigation of how to enhance cultural identity and create a sense of place through heritage, shared activities and stakeholders' interactions are in the focus. Besides revealing the relations between stakeholder/user interactions (Note 1) and cultural, social and economic activities in public space in relation to sustainability, another intention of this article lies in combining sustainable design and 
architecture/urban planning methods with social science approaches, an endeavour which is still in its beginning and exploratory stage in the scientific community of architecture and design. The analysis and findings of this case study will contribute to opening both an interesting field for research and a promising arena for practice for designers and architects to explore complex relationships between sustainability, people and place.

One characteristic feature in the relationship between place and activities in traditional towns such as Kathmandu in the present context is a decline of mental/spiritual values, which is by some users connected with an increase of economic activity and which is sometimes accompanied with ecological decay (Singh, 2013). As other South Asian societies, Nepal and especially Kathmandu comprises complex cultural accretion. Kathmandu displays multiple morphological forms because of various people's needs, activities and institutions. Since the 1980ies, Kathmandu, as many of the traditional towns in South Asia has undergone transformations affected by rapid population growth and economy based development (Bjoenness \& Corneil, 1998; Thakur \& Bjonness, 2001; Skjold, 2010; Singh, 2013), which change among others expectations to public space, land use, and civic life (Thakur \& Bjonness, 2001). While the impacts of globalization are challenging traditional urban systems, they create also a growing awareness of people's cultural values, explicated e.g. through initiatives by local users to generate their own solutions for 'place making (Hamdi, 2010).

In case of Indrachowk square, conservationist and intellectuals agree that the built environment in Indrachowk undergoes increased commercialization due to a loss of traditional values and meanings (Tiwari, 2012). One can further observe dilapidated physical structures due to conflicts among individuals and groups, while the neighborhood becomes increasingly multicultural. The reciprocity between the cultural beliefs, social-political activities and the qualities and uses of the physical space Indrachowk expresses itself through different activities, which can be studied and, to a certain degree deliberately influenced.

A case study of the area of Indrachowk Square, Kathmandu with a special focus on the Akash Bhairav temple is the background for the analysis. The temple symbolizes a particular example for both cultural sustainability and negotiating public space. Following the introduction, we present the case study in the second section of the article. In section three, three influential social groups the Akash Bahirab Guthi - a socio-cultural group, the Shree Akash Bhairabnath Indrachowk Club - a local youth group and Bhajan Khala- a socio-religious group and their activities are examined and their relationship to the other users is discussed. The Akash Bhairab Guthi, the Shree Akash Bhairab Indrachowk Club are in the focus because they mainly initiated and managed changes, together with other individuals, who wanted greater influence in decision-making processes and thus increasingly participated in cultural and spiritual activities related to Akash Bhairab temple. In the backdrop of the access to the open space, we answer questions such as which activities led to major changes in the access to public space, which users were involved in the process, and what was impact of these changes, deliberately or not. Findings of negotiating access to urban public space between different users and consequences for sustainability are discussed in section four and a conclusion is presented in section five.

One of the results of this study is that triple-bottom line sustainability is profoundly influenced by cultural activities. Further, on a stakeholder level and considering the acceptability of sustainable development, there must be access opportunities for the various users of space. However, access to space comes not as equal right for all per se, but it as has to be recognized as dynamic possibility for competition and negotiation to use it. Third, in order to get and maintain access, competence development related to knowledge, values, feelings and cultural beliefs connected with the space play an important role, and getting this competence can, in turn, be encouraged by fostering specific cultural and sustainability related activities.

This article addresses two gaps in sustainable urban planning and development. First, the implementation of sustainable urban solutions has not been satisfactory in Nepal, partly because cultural contexts have not been sufficiently taken into account (Nepal, 2013). Experiences show further, that technology and financial capital alone are insufficient for durable implementation of sustainable solutions, and that local actors play an essential role for implementing and maintaining those through living in their specific physical and symbolic artefacts (Brent, 2012). Therefore, the authors considered it as crucial to investigate local actors' cultural activities and interactions and analyze how they contribute to cultural sustainability. The other gap is that planners often see themselves as providers of solutions or technology (Forrester, 1985; Hamdi, 2010) while they have de facto no executive power but rather are enabler and facilitators of discourse and interactions among different stakeholders in the system (Hamdi, 2010). Rather than a technological interpretation, planning has to be considered as a political issue that needs interests, commitment and consensus from the affected groups regardless of their expertise (Forrester, 1985). A technical solution cannot stand-alone unless it is built on the political support from the influential groups in the affected area. The authors have chosen a discursive approach to planning to meet 
these gaps and to emphasize the communicative role of the urban planner and designer in a sustainability context.

\section{Method}

In order to investigate the intricate and often implicit bonds between people and place, this article analyses a case study of the Indrachowk Square, Kathmandu, Nepal, by means of observation and semi-structured interviews. Indrachowk Square represents here not only an actual example of a purposely-designed urban space for cultural, social and economic activities but also as an illustration for transitional issues of public space transgressing from traditional to post-traditional constellations (Keitsch, 2006). The case study was an in-depth study of a small set of observations and interviews, which is usually considered as a limitation related to the validity of findings. However, the main criterion was to interview and to observe an exclusive actor group (Guthi), whose members are very restrictive related to whom they allow access, and to analyse their activities and interactions with other stakeholders related to the square, rather than to gather a huge amount of data.

Observation means here the methodological examination of a group of individuals and their practices in real-life settings. Participant observation was used to understand the involved stakeholders and the process being investigated. The nature of participants' observation allows the researcher to place greater emphasis on depth rather than on breadth of data and information (Descombes, 1998). In our case, the observations took place in the category 'participant as observer' (Gold, 1958) to preserve the natural context of the situation. The observed situations involved participants, not only with different roles, but also of different ages and groups. The first author gained access to the setting by being a member of the Guthi i.e. by virtue of having a natural and non-research reason for being part of the setting. Experiencing these processes and negotiations at least sequentially from an insider's perspective, makes a researcher aware of crucial factors.

The purpose of a semi-structured interview is to obtain people's descriptions of their life worlds and to interpret the meaning of the described phenomena (Kvale \& Brinkmann, 2009). Such interviews come close to an everyday conversation, but differ because the researcher has a professional intention and ask open question about predefined themes (Kvale \& Brinkmann, 2009). The role of the researcher is to ask a series of structured open questions and to probe more deeply into respondents' beliefs, attitudes and inner experiences by following up their answers. The first author spent two months (20 May 2012 - 19 August 2012) in the field gathering information regarding the changes that had happened in the qualities and uses of built environment in Indrachowk square and its neighbourhood and documenting and analysing field notes. Further, he conducted seven semi-structured interviews in the same period. The interviewees were identified through the groups they belong to, related to the following themes: Competition, conflict, exchange and cooperation. The interviews were open and had the intention to investigate activities of these groups, relating mainly to three questions: how and why did the group come to the place, what did they do to get access to the place, and what activities were they currently performing to maintain their access status.

The results presented in this study were constructed in a process wherein the authors moved between analysing observations and semi-structured interviews. The conversations with stakeholders were transcribed and the first author developed a network diagram (see section 3.3.) to account for both verbal and nonverbal stakeholder activities and negotiations, as well as contextual aspects. Rather than a mirror of reality, this network diagram can be understood as a reflection of the experience from which it originates.

According to Morse (1995), a crucial principle to understand the process of saturation is that "Richness of data is derived from detailed description, not the number of times something is stated". (p. 148). In line with the description of saturated data as "rich, full, and complete" (Morse, 1995, p. 149), the authors concluded that case was suitable for developing a reasonable model. The issue of dependability refers to the ways in which the research process can be audited (Guba \& Lincoln, 1989; Koch, 2006). Through presenting a clear account of the stakeholders groups and the negotiations that took place, the researchers hope to establish auditability of the case study. Finally, the study has limited transferability, or fittingness, i.e. the extent to which the findings are available for comparisons with other contexts and the extent to which an audience views the findings meaningful and applicable (Koch, 2006). The findings of this study can most likely fit into other urban planning and cultural sustainability contexts, which relate social science methods to architectural and design challenges.

\section{Results}

Tiwari (2012) claimed that the traditional public space of Kathmandu provides the economic and social environment that can assimilate the heterogeneity, diversity and density of economic, castes, job, and other cultural differences. Historically, Indrachowk was one of the important nodal points of Indo-Tibet trade route from the mid seventh century until the end of 19th century. Apart from the vibrant economic environment, the 
square as a public space still has religious importance with temples like Kantishwor Mahadev, Bansheswor Mahadev, Betal, Ganesha and most importantly Akash Bhairab Temple. The square is also part of one of the famous chariot festivals of Kathmandu, called Indrajatra.



Figure 1. Aerial picture showing Indrachowk Square and its vicinity

\subsection{The Changing Face of Indrachowk}

Public space reflects the people's way of living, cultural beliefs and values, changes in the public life will ergo transform the design and management of public spaces. Disordered, heterogeneous traffic streams, increased building heights, and a growing number of shops are the characteristics of today's Indrachowk. The streets once used for pedestrian and chariots are congested with vehicular traffic and parking in haphazard manner. Traditional traffic management can no longer handle the increasing modern day traffic resulting damaged roads and heavy traffic jams. At present day the square is engulfed with encroachment. The encroachment and overcrowding of streets by the wayside informal vendors limits the use of these spaces for leisure and recreations. Increased traffic and accompanying pollution is an additional factor to hinder such activates.

In general, Indrachowk faces today what Tiwari (2012) called 'wanton commercialization'. Some of the micro spaces on the square, which are of social and religious importance, are converted to the space for economic uses. Even though the area of the overall square has not changed, the increasing buildings heights surrounding the square and building projections in the upper floors have made it appear more congested and chaotic. The growing economic pursuit, encroachment and unmanaged commercialization, and the increasing traffic contributed to convert Indrachowk into an ordinary open space of economic value and congested street, which seems devoid of any cultural values, beliefs and meanings, which were once balanced with commercial, religious and social activities.

\subsection{Negotiations of Space: Variations in Control}

At Indrachowk Square, an increasing competition among different users has limited the opportunities of access to this space. The square is same, but the interests are diversified with different users wanting to use space differently. So, in today's context, one of the main questions for the management of this square are who gets access to use this space, under which conditions and what are preferred activities to be performed at Indrachowk.

The streets and squares have always been a market place. According to Nepal Street Vendors Trade Union (NEST), in Kathmandu valley alone, there are 30,000 street vendors and more than 20,000 in Kathmandu metropolitan city alone (Adhikari, 2012). In Indrachowk, there are street vendors coming from different parts of country and even from India. Street vendors are one of the most important parts of informal sector economic activities. There are conflicting opinions among people if vending activities should be allowed on the streets or not. A walker or the vehicle user might see them as nuisance when they had to walk or drive on the roads through the street vendors. On the other hand, there are thousands of vendors whose livelihoods depend on the streets, which makes it impossible to completely abolish the informal street markets. Moreover, the street 
markets also provide the varieties of goods, especially fresh fruits and vegetables in the local market at an affordable price. Their abolishment would thus eliminate different economic and developmental aspects of the street life, especially in the informal sector (Note 2).

The Shree Akash Bhairab Indrachowk Club, a local youth group in the area (Note 3), has established a feasible solution by imposing a schedule mechanism to balance the claims from different groups to use Indrachowk. The street market vendors are allowed in the morning till 9:00 AM. The logic behind this mechanism is that most of the consumers buy fresh vegetables and other items in the morning when the traffic congestion is least. After 9:00 AM, traffic density is high due to the start of office hours (Note 4). The club charges Rs 20 (Note 5) per day for the sweepers and guards from the vendors.

However, within the square, Shree Akash Bhairabnath Guthi has claimed a part of space in front of the Akash Bhairabnath Temple, which is used for various social and religious activities and exclude vendors and other public users. Despite of the claim, the space is occasionally used for motorcycle parking if no activities take place. On a normal day, there is a temporary shop selling butter lamps and a sweet dish that are used as offerings to the shrine. This shop is run by the Akash Bhairab Guthi, a local socio-cultural group associated with the temple, and this activity ensures as well that no other economic user could use that space. The claim is reinforced during Indrajatra festival, when a stage is prepared within the boundaries for the Akash Bhairabnath shrine. The claim of the Akash Bhairab Guthi represents further an attentiveness to preserve their cultural beliefs and identity from the growing economic claims. Other users of the space take the Akash Bhairab Guthi's claim as a given force.

Within the square, the plinth of Bansheswor Mahadev Temple is a particularly interesting segment because here an economic group has gained special user rights compared to others. Apart from representing monumental character, the high raised plinth of the temple serves various activities like seats for viewing various social activities, space for rest, taking siesta and shelter for rainfall. However, on a usual afternoon the plinth is covered with pashmina shawls (Note 6), making it almost impossible for a stranger to distinguish if it is a temple or an open shop. There are altogether eleven shops, and every shop is using a part of the space, negotiating with each other and tacit to outsiders. They are not the legal owners of the plinth however the shopkeepers can transfer their use-rights to any other shopkeeper. A non-negotiable criterion is that the shop should sell clothes. It is interesting to note that the user rights can be sold to any other person who is willing to sell pashmina shawl there and even if the pashmina shawl vendors are not the owners other street vendors accept their user-rights.

A major reason for their user-right is the support from the two local groups, the Shree Akash Bhairabnath Bhajan Khala (a socio-religious group) and the Shree Akash Bhairabnath Indrachowk Club (a local youth group). This fact has been even verified by one of the municipality officials (Note 7). According to him, the municipality has cleared off the shops once or twice but due to the strong support from the local groups, even though it is illegal to use public space for economic purpose, the shops prevail. There are basically two main reasons for the shop keepers' strong bondages with these local groups. Firstly, they participate in various social and religious group activities and donate for feasts and rituals. Secondly, these shops have existed on the square for more than thirty years and most of the people know them, even though the shopkeepers change and are not necessarily from this locality. From the pashmina shawl shopkeepers' view, they have gained control on the use rights by getting involved in activities organized by the local groups. Creating strong social networks with the Shree Akash Bhairabnath Bhajan Khala and the Shree Akash Bhairabnath Indrachowk Club has helped them not only to maintain their position in the market but also to establish long-term user rights compared to the other street vendors.

An analysis of how this space is used reveals variations in the extent of control, where the degree of control stands proportional to resilience of the users' stake. The users with most access are those with the highest stake i.e. those most familiar with the diverse activities of the place, and most motivated to maintain them. This fact contradicts the claim of some urban planners for a right of all users to control space (e.g. Luca, Gaman, F. Singureanu, 2012). On the contrary, from our point of view, variations in the extent of control are one of the reasons behind the sustained existence of the diverse activities of this space. A scenario, where the local groups would not perform their religious rituals due to the presence of street vendors is not desirable for any user, and neither is one where street vendors occupy the space during heavy traffic hours. Therefore, it seems rather necessary to control that the present users do not deprive other users of getting access to the basic opportunities of this space, than to make sure that every person have the right to use every part of the public space.

Indrachowk Square is an example of public space, where the variations in control are achieved by different users but without the complete or extensive exclusion of other users. An example of that is the timely schedule for the 
street vendors to sell their products even though the government officials have labeled that illegitimate. That judgment and management of variations of users control is done by the local constellations of social groups.

\subsection{Key Users: Acquiring Power and Negotiating the Access to Space}

The Kathmandu Metropolitan city has the right to clear off any kind of street vending and encroachment done for economic opportunities. However, in case of Indrachowk, the municipality was present only in very few instances (Note 8). Local groups often through informal activities manage the Indrachowk square space. A closer look at the way these different groups negotiate with each other. The figure below reveals a network and the strengths of its relationships in terms of user rights and variations of control. Disagreements appear of course as well in the way different user-groups use the space, or are allowed to use the space.



Figure 2. Network Diagram of key users

The municipality has the highest degree of authority in controlling the street vending, but their impact and influence is superficial or weak (dotted lines), which exposes from our point of view the indifference of the municipality. Imposing the regulations against the street vending emphasize the bureaucratic technical solutions of the problem of street vending which ignores the political dimensions with in the local context in spite of its sincerity and good intentions. Apart from being the bureaucratic in nature, the rational management procedure also fails to address the practicality of the actions especially related the locals' way of living in terms of their dependency on the street markets for their regular groceries and other household items while the management mechanism does not address that local actions and need. Moreover, the information flow to the users and the local groups is unidirectional as the municipality authority imposed the regulation as the solution rather than developing through public debate and argument within the local context. The concerning authority despite all its good intentions have indirectly perpetuated the exclusion public political participation and action. The introduction of the timely mechanism through the local groups informally could be seen as the outcome of this inability of municipality authority to address the local practical actions and its unidirectional interaction nature in addressing information. 
The highlight of the above network diagram is the triangular constellation of the three local social groups (Note 9). A question might arise why these three local groups bring forward a higher stake and control than any other users. Among many reasons, non-local and local groups recognized their common cultural background as the primary reason for engagement and higher stake. It is important here to mention that Newars dominate all local groups. They are considered as the original inhabitants of Kathmandu valley and popular for their cultural heritage. The cultural beliefs and values of Newars are directly linked with the activities in the public space (Tiwari, 2012). Therefore, through cultural beliefs and values, these local social groups dominated by Newars are inherited with the information, experiences and sense of attachment to Indrachowk Square. Considering culture as 'the way of life' (Nurse, 2006) they are attached to the public space in every aspect of the life and contribute with great strength and commitment to the development process of this space. This has made them the primary users with greater control, commitment, motives and responsibility in any kind of decision-making process related to the open space that includes negotiating on using the space. Another feature of these local groups is their two-way interactions with other users such as economic groups like the pashmina shawl group, which would build the trust among them. The goals and activities of these three local groups in Indrachowk are discussed below.

\section{Akash Bhairab Guthi - A socio-cultural group}

The history of traditional Guthi goes back to rule of Lichchhavi period, around fifteen hundred years ago. The Guthi successively institutionalized management, operation, and maintenance of city space, of secular and religious artefacts, of activities, and festivals and of other urban services on the community level by setting up norms for rituals (Nepali, 1965; Tiwari, 2006). These activities link the Guthi to land, spaces and acts of assembly and socialisation (Tiwari, 2012). The Guthi has a tacit interest in preserving the norms and values of community (Nepali, 1965; Tiwari, 2006). It binds the people at different levels: caste, patrilineal (hereditary through father in patriarchial society) lineage and territory (Nepali, 1965; Toffin, 2005). So, it is an exclusive institution bound by rituals and culture similarly.

Akash Bhairab Guthi is also an exclusive Newar (Note 10) society of Jyapus (Note 11) with the place bound to Indrachowk territory and the patronage linked to the Akash Bahirab Temple. Currently the institution consists of 60 members. This Guthi used to have land gifted for performing various activities. However, it has lost its land due to haphazard privatisation. Moreover, the instituion is mainly bound to perform the rituals, festivals and other activities bound to Akash Bhairab Temple and do lack financial resources.

\section{Shree Akash Bhairab Indrachowk Club- A youth group}

The club initially started as a sport club by youths and was registered in 1977. It is important to note that most of the founding members were related to Akash Bhairab Guthi, as the sons of the Guthi members. Today the members comprise of different users including women, retired people, shop owners, youths from the area. The club has diversified social and environmental activities such as solid-waste management, garbage collection and is organizing various social events like blood donation programs, managing street vendors. Shree Akash Bhairab Indrachowk Club is acting voluntarily in various feasts and chariot festival and works as the mediator for any kinds of conflicts. One of the interviewees claimed that the diversification of the activities is mainly due to the inefficiency of the local institutional body and the decreasing trust of the people in local governmental authorities. The lacunae in the relationship between local people and local government have urged local social groups such as the club to take social actions and act as mediator.

\section{Shree Akash Bhairab Bhajan Khala- A socio-religious group}

Shree Akash Bhairab Bhajan Khala is a group mainly focused on continuing the tradition of religious activities of hymn singing. With the growing economic claims from trader, hymn singing lost its ground and even identity. So, the group started with the funds from donations in 2000 and has successively captured interest of other users, especially younger people from different parts of Kathmandu, transgressing the local boundaries of Indrachowk. A major contribution of the Shree Akash Bhairab Bhajan Khala group are activities during the Indrajatra festival when they prepare a setting for singing hymns for eight days and invite groups from other places for the performance. The groups itself have undergone changes in their internal structure by opening up to other ethnic groups as well based on Hindu-Buddhist religious practices.

The current appearance and management of the Indrachowk square can be seen as the outcome of the negotiations of space and is influenced by power relations managed by some of these local groups. However, the question arises if the local groups understand that their dominant role as gatekeepers (Shoemaker et al., 2009) might be connected with the task to providing use opportunities for other users, correspondingly to what e.g. the pashmina shawl group (economic group) enjoys. The informal regulations deployed by the local groups, 
irrespective to the governmental regulation, control opportunities for street vendors and others to use the space and regulations often entail variations in the user rights. Clearly, the eleven-pashmina shawl shops have greater control because they can use the space whole day, while other economic users are restricted (Note 12). Moreover, the shopkeepers do not pay rent but rather give donations to the socio-religious group for organizing various religious activities. The control of the shopkeepers is de facto grounded on their profound information on the local groups' values, feelings and experiences related to the place.

It is interesting to note here that most of pashmina shawl shopkeepers are not local residents but have this information due to their prolonged involvement in various activities with the local groups. The experience and the respect for local values have established trust between these groups. The other street vendors and users lack that information and trust which puts them in lower rank in terms of control of the use of space (Note 13). Clearly, the better informed have better control user rights in case of Indrachowk square.

The use of public space for economic purpose is illegitimate and users have every chances of being cleared off by government authorities. This applies for the pashmina shawl shops, the street vendors and even for the socio-cultural group. However, the sense of certainty varies for these different users. The degree of security decreases from local groups to pashmina shawl shops to street vendors, and stands proportional to the information (including values, feelings and experiences) available to them about the place and to the variation in the user-rights.

\section{Discussion}

A primary concern for any individual or group is to have the spatial rights, access and control to perform activities (social, economic, or religious). However, a realistic scenario in which each individual or group has the same control rights is unlikely. There are de facto variations of control and they are dynamic in nature and shifts among different users. Managing spatial control requires further information of values, feelings and experiences, additionally facts and techniques. Increased power comes with increased responsibility and commitment and the local groups in our case have come in fore to take that responsibility. Many users have accepted these local groups as real forces, but may also feel vulnerable under their management and control system. The local groups have the power to impose mechanisms or control systems with a great impact on the spatial control as in case of Indrachowk. However, the question remains if these local groups are competent enough to manage the space, considering various opportunities for different kinds of potential users. Another question is if these groups neglect current and important environmental issues since these are not part of their value system and nature as the 'third party' is left out.

Giving the managerial power to local groups without any monitoring can lead to exclusion of users. An example is the use of a part of open space by the Guthi, who are selling butter lamps. Here, the other users have to get permission to use that space, so this socio-cultural group has restricted the place for other users. Local groups also tend to be static and many of their members may argue that how can they trust future users whom they do not know as in case of the street vendors. The present users might not feel emotional obligation for those, who are to come (Note 14). Providing complete control to local groups might thus increase the vulnerability of other groups that are in lower order of the hierarchy. Establishing external control mechanisms for local groups might contribute to meet this challenge. Another way is the internal alteration of the groups, which tend to be quite static, by other users of the space, and a third possibility is launching a local control system that could attempt to provide basic opportunities for the potential future users.

Common participation of different users in various activities seems to be a promising way to create mutual trust and may lead to sharing access. With the changing social environment, the local groups also undergo internal alteration in order to adapt to changes. For example, the Indrachowk club diversified its activities and act as a mediator in conflicts, while the Bhajan khala asserts itself in order to continue the disappearing hymn singing, while also allowing people from other areas to participate. The involvement in such activities presents an opportunity for users to gain access in a similar way as the pashmina shawl shopkeepers did. So on one hand the local control system should maintain cultural activities through which present users get access to space while users can get involved to access information about the place. This two ways trust-building between the local groups and the other users is important in order to manage the use of public space as in case of Indrachowk square correspondingly and sustainably.

When discussing sustainable development, there has to be equal opportunities for different users in using the space in Indrachowk Square for various activities. What the authors call the 'equity to use for sustainable development' comes here in the form of legitimate competitions and negotiations to use the space among different users. In order to get access to the use of the space, the knowledge of values, feelings and cultural 
beliefs of the place play an important role. Therefore, in practice one needs to understand that planning actions are not only technical issue but also needs to consider everyday activities and needs of the local users as well. An expert cannot solve these questions without ignoring the political dimensions within the context. The case of imposing street vending, which was idealistic and did not conveniently met the social and political reality of Indrachowk has illustrated this pertinently.

\section{Conclusion and Outlook}

Sustainable development is focusing on environmental, economic and social equity. In order to achieve this triple-bottom line equity it is critical to understand how a significant social system evolves and how it can be influenced. In the Indrachowk case, social equity is influenced by the fact that local groups have embodied information, developed throughout generations as their 'culture'. The notion of 'embodiment' refers here to a phenomenological concept of spatiality and to humans' experience of place. Places are seen as '.. fusions of human and natural order and are the significant centers of our immediate experiences of the world' (Relph, 1976:14). The very quality of place lies in the potential to organize human values, experiences and activities spatially. According to Relph (1976) we feel inside a place, when we experience it, interact there, feel safe, enclosed and at ease. In addition, the more profoundly 'inside' a place we feel, the stronger will we identify ourselves with the place. On the contrary, when we feel alienated, insecure, separated from world - we experience outsideness. The important point is that certain places can take on different identities for different users and that these identities change dynamically, relating to embodied information and activities that connect these users with places. From a cultural point of view, a phenomenological view requires to broaden the concept of culture beyond 'arts', and 'heritage', towards a 'way of living'. 'Culture' entails then underlying belief systems, values, experiences and worldviews, which contribute to shape relationships as well as interactions and practical actions within the environment (Nurse, 2006).

Economic opportunities may influence social sustainability to a great deal, however, one's culture is just as important as instrumental considerations, and can strongly affect social practices as well. The variations in control of the user rights in the Indrachowk case illustrate one example of social sustainability, namely how 'equity in using space' is practiced as 'negotiations of space' (Singh, 2013). Problems will not be met by applying mere bureaucratic and technical solutions. Rather, the overall procedure needs pooling of expertise and other non-professionals' contributions, gathered informally through mutual consultation and involvement. Rational management procedures have to be supplemented with the existing local politics and working consensus. Moreover, support building and commitment in addressing the social and political reality seems to be a good way to create viable solutions (Forrester, 1985).

The current management and structure through local groups 'on negotiations in the use of Indrachowk Square' illustrates the importance of cultural parameter in the rational management mechanisms of street vendors. The case of Indrachowk square does here not only illustrate the need to incorporate the local cultural context into an overall sustainable development framework, but also emphasizes the fact that the local culture knowledge could be the basis for the meaning and the practice of sustainable development locally. However, the case also illustrates the fact that the degree of control also shifts continuously according to changing cultural beliefs: new groups come in the foreground with different activities, and change and alter the space. These changes can and should be monitored to reveal undesirable shifts like growing inequity, incongruence, and rising exclusion. Sometimes local level control may lead to the self-destructive pathways, misusing the space, and asserting social injustice and even environmental decay. There are few instances of the commercialization of the religious spaces for example the plinth of Bansheswor Mahadev Temple. These kinds of instabilities and conflict do require interventions as ultimate regulation mechanisms to provide the future sustainability of space for all users. Conclusively, the case of Indrachowk square also indicates that the quadruple bottom line of sustainability will acquire greater emphasis in the future. Projects that deal with sustainable urban or rural planning and development will henceforth have to consider solutions that both are related to sustainability and to the community's wellbeing, i.e. to pay attention to cultural viability, economic affluence, environmental resilience and social equity.

\section{Acknowledgments}

Special thanks to Sharad Kumar Dangol, Vikash Bhakta Shrestha, Shyam Maharjan, Purna Maharjan and many other users of Indrachowk Square who helped in conducting the study and providing valuable information and time. Thanks also go to Dipa Shakya and Shreem Rana who has accompanied and assisted in collecting information. 


\section{References}

Adhikari, D. (2012). Income generation in Informal sector: A case study of the street vendors of Kathmandu Metropolitan City. Economic Journal of Development Issues, 13, 1-14.

Bjoennes, H. C., \& Corneil, J. (1998). Urban Ecological Planning and revitalization: A New Frame of Mind in Planning Education in Developing Countries. Regional Development Dialogue, 19, 58-67.

Casey, E. (1998). The Fate of Place. London: University of California Press.

Day, C., \& Parnell, R. (2003). Consensus Design, Socially inclusive process. Architectural Press, Burlington.

Eason, K. (1987). Information Technology and Organisational Change. Taylor and Francis.

Gold, R. (1958). Roles in sociological field observation. Social Forces, 36, 217-213. http://dx.doi.org/10.2307/2573808

Hamdi, N. (2010). The placemakers' guide to building community. London: Earthscan.

Hippel, v. E. (2005). Democratizing Innovation. Cambridge, Mass.: MIT Press.

Keitsch, M. (2006). Changing Technology Perceptions, Progress in Industrial Ecology. An International Journal (PIE), 3(1/2), 41-58.

Lefebvre, H. (1991). The Production of Space. Oxford: Basil Blackwell.

Luca, O., Gaman, F., \& Singureanu, O. (2012). Coping with Congestion: Shared Spaces. Theoretical and Empirical Researches in Urban Management, 7(4), 53-62.

Nepal, U. (2013). Social acceptance of community-based DEWATS - A case from two urban communities of Madhyapur Thimi municipality of Nepal. Trondheim, Norway: Norwegian University of Science and Technology.

Nepali, G. S. (1965). The Newars-An Ethno-Sociological Study of a Himalayan Community. Bombay: United Asia Publications.

Nurse, K. (2006). Culture as the fourth pillar of sustainable development. Small states: Economic review and basic statistics, 11, 28-40.

Oppenheimer Dean, A., \& Hursley, T. (2002). Rural Studio: Samuel Mockbee and an Architecture of Decency. New York: Princeton Architectural Press.

Parajuli, Y. K. (1986). Bhaktapur Development Project: experiences in preservation and restoration in a medieval town (1974-1985). Kathmandu: Ratna Pustak Bhandar.

Relph, E. (1976). Place and Placelessness. Pion, London.

Shoemaker, P. J., \& Vos, T. P. (2009). Gatekeeping Theory. New York: Routledge.

Singh, B. (2013). My Society: My Place- Understanding local level urban change in Indrachowk, Kathmandu. Trondheim, Norway: Norwegian University of Science and Technology.

Skjold, L. (2010). Kathmandu Bazaar - making 'space' for cultural heritage in a commercial urban context. Trondheim, Norway: Norwegian University of Science and Technology.

Thakur, N., \& Bjonness, H. C. (2001). Understanding Boundaries of difference in efforts of cultural continuity, cases of traditional settlements in India and Nepal. Adelaide, South Australia. 3rd International Symposium on De-Placing difference, architecture, culture and imaginative geography, Centre for Asian and Middle Eaastern Architecture, Adelaide University.

Tiwari, S. R. (2006). Transforming cultural heritage into sustainable future: A Case study of Patan, Nepal. In M. Nadarajah, \& A. T. Yamamoto (Eds.), Urban crisis: culture and the sustainability of cities. S.l.: United Nations University Press.

Tiwari, S. R. (2012). Characteristics and Challenges- Public Spaces of Kathmandu valley Towns- A Socio-cultural perspective.

Toffin, G. (2005). From kin to caste-the role of Guthis in Newar society and culture. Kathmandu: Social Science Baha-Himal Association.

UNESCO. (2012). Culture: a driver and an enabler of sustainable development. Thematic Think Piece. UNESCO.

Vesely, D. (2004). Architecture in the Age of Divided Representation, the Question of Creativity in the Shadow of Production. Cambridge, MA: The MIT Press. 
Wessels, T. (2006). The Myth of Progress: Toward a Sustainable Future. Hanover: University of Vermont Press.

\section{Notes}

Note 1. In this article we do not differ explicitly between the terms 'stakeholder' and 'user'. Of course we are aware that the term 'user' implies quite different views. The most common explanation means a person who interacts directly with a product or a service. Eason (1987) placed users in three categories: (1) primary users, i.e. frequent hands-on users; (2) secondary users, using the product/service through a mediator; and (3) tertiary users, people who are affected by the product/service and might influence its purchase. Business theory classifies among others between 'lead users', people who are pioneers for products/services that might become trends later on (von Hippel 2005, 22), and 'end users', who finally employ the product/service. However we are not in the product design realm and the term 'user' is employed in this article for individuals and groups who do have an interest in, but also operate in Indrachowk, while 'stakeholder' is employed for people who have an interest in the situation and its development.

Note 2. According to Adhikari (2012), in the urban context the informal sector refers to small enterprises selling food and goods or offering services and thereby involving the cash economy and market transactions.

Note 3. For description of local groups see section 3 of this article.

Note 4. In Nepal the government office working hours is from 10:00 AM to 5:00 PM in summer while 10:00 AM to 4:00 PM in winter. In case of private organizations, the office hours start from 9:00 AM.

Note 5. Current conversion rate $-1 \$=$ Rs 95 approx.

Note 6. A fine cashmerewool material for textiles.

Note 7. Interview 4.7.2012.

Note 8. In an interview with one of the pashmina shawl shopkeepers, in his 20 years of business, twice municipality officer for street vending only took him away. When asked about the municipality officer who keeps an eye on the street vending in Indrachowk area, his remark was that the local community group and people have not complained about them. Indirectly they are protecting them.

Note 9. The authors do realise the fact that there might be other social groups within the area. However, especailly in the context of street vending on the plinth of Bhuwaneswor Temple, the authors come upon these three local social groups who have influence on negotiating the access to the use of open space.

Note 10. Newar is a homogeneous community of a number of former ethnic groups, formed through centuries with a common Tibeto-Burmese language and other traditions (Nepali, 1965). They can be both Hindu and Buddhist, divided into different castes (jaat) on the basis of hereditary occupation, marriage circles and ceremonial purity and have to follow specific rules based on the social practices. Each Newar is associated with a Guthi - the institutionalized body to manage, operate and maintain secular and religious artefacts and activities with the hidden interest of preserving the norms and values of community (Nepali, 1965; Tiwari, 2006).

Note 11. Farmer castes in Newar society.

Note 12. The other users can use the plinth of Bansheswor Mahadev temple can use the space only if the current users of the plinth don't put their merchandise there and give consensus for other user to use that space.

Note 13. In an interview with one of the members of Shree Akashbhairabnath bhajan khala - a socio-religious group, he stressed that the pashmina shawl shops are there for very long time, and the group knows most of the activities related to them place and even participate. Other street vendors could not be trusted as they frequently move in and out of the place and perhaps at the time of participation of activities, they would turn their back.

Note 14. The way the local groups interact with pashmina shawl shops differs from the way they do with other street vendors.

\section{Copyrights}

Copyright for this article is retained by the author(s), with first publication rights granted to the journal.

This is an open-access article distributed under the terms and conditions of the Creative Commons Attribution license (http://creativecommons.org/licenses/by/3.0/). 